\title{
Handbook of Adolescent Medicine and Health Promotion
}


This page intentionally left blank 


\section{Handbook of Adolescent Medicine and Health Promotion}

\section{David MN Paperny, MD, FAAP, FSAHM}

University of Hawaii, USA 


\section{Published by}

World Scientific Publishing Co. Pte. Ltd.

5 Toh Tuck Link, Singapore 596224

USA office: 27 Warren Street, Suite 401-402, Hackensack, NJ 07601

UK office: 57 Shelton Street, Covent Garden, London WC2H 9HE

\section{British Library Cataloguing-in-Publication Data}

A catalogue record for this book is available from the British Library.

\section{HANDBOOK OF ADOLESCENT MEDICINE AND HEALTH PROMOTION}

Copyright (C) 2011 by World Scientific Publishing Co. Pte. Ltd.

All rights reserved. This book, or parts thereof, may not be reproduced in any form or by any means, electronic or mechanical, including photocopying, recording or any information storage and retrieval system now known or to be invented, without written permission from the Publisher.

For photocopying of material in this volume, please pay a copying fee through the Copyright Clearance Center, Inc., 222 Rosewood Drive, Danvers, MA 01923, USA. In this case permission to photocopy is not required from the publisher.

ISBN-13 978-981-4317-98-6

ISBN-10 981-4317-98-5

Typeset by Stallion Press

Email: enquiries@stallionpress.com

Printed in Singapore. 
To my son, Jerry,

who taught me the most about adolescence, and how to really walk the walk and talk the talk! 
This page intentionally left blank 


\section{Preface}

Because of new adolescent and young adult health and societal issues, medical diseases are no longer the main health threats to their well-being. We must preempt and respond to the consequences of behavioral choices faced by more and more adolescents worldwide, such as the complications of unintended pregnancy, STDs including HIV, alcohol and drug abuse, and emotional issues including suicide and eating disorders. There is the risk of future heart disease related to smoking, exercise behaviors, and nutrition, as well as the negative consequences of so many accidental injuries, particularly those related to motor vehicle accidents. This ongoing health crisis requires a fundamental change in the emphasis of adolescent health services - to services which are directed at the prevention of the major health threats facing today's youth. This handbook, therefore, focuses on such services, as well as uniquely-adolescent aspects of medical conditions, rather than detailed evaluation and management of routine medical illnesses and diseases, which can be gleaned from other medical textbooks.

The health issues of contemporary adolescents and young adults require health providers, paraprofessionals, schools, families, and communities to develop practical methods to preemptively improve the health habits and well-being of youths. Please take this handbook with you on your journey.

I would like to acknowledge and sincerely thank the following reviewers of the content of this publication:

Robert J. Bidwell MD, FAAP

Board certified in Adolescent Medicine

Associate Professor of Pediatrics

University of Hawaii, John A. Burns School of Medicine

Douglas Chun MD, FAAP, FAAD

Board certified in Pediatrics and Dermatology

Hawaii Permanente Medical Group 


\section{Warren M. Seigel MD, FAAP, FSAHM \\ Director Adolescent Services \\ Coney Island Hospital, New York \\ Frank Uhr MD, FAAOS, JD \\ Board certified Orthopedic Surgery; Fellow in Sports Medicine \\ Hawaii Permanente Medical Group}

Adolescents are neither large children nor small adults.

David Paperny

A bonus CD with useful resources, handouts and videos is available to book customers upon contacting the author at DavidPaperny@aol.com 


\section{FOREWORD}

Personal histories prove that the innocence of childhood does grow into the curiosity and risk-seeking of adolescence. Parents often feel like a failure when their children do not grow into the teenager or young adult that they wanted them to be! In the past, developmentalists, or those in the health professions who have been interested in such matters, have essentially focused on the biology of change. With the availability of new imaging technologies, there has been an increased interest in correlating biology with manifest psychological development and behavior. The core determinants of change are being defined - the very determinants that brought us to our present position.

For many of us, the struggles and behaviors of today's youth are foreign. As Dr. Paperny points out in this book, these determinants of change are taking place in a different world - a different social ecology, so to speak — a world that is defined by individual communities, cultural and religious beliefs, families, school environments, recreational opportunities, access to health care, economic resources, media exposure, peer interaction and life opportunities. It is these unique social ecologies that impact the identity-seeking adolescent and influence the trajectory of his or her personal change. Hence, while the core experience of adolescence remains unchanged, the expression or adaptation to that experience differs not only from generation to generation, from community to community, but from country to country.

Simply put, the need for the journey through adolescence does not differ from yours or mine. The options for travel are different and maybe more treacherous - what we, as professionals, call risk-taking. Seen through their eyes, young people merely experience this risk-taking as options for their development, for their growing up, and for peer acceptance. Thus, no longer can we view adolescence as the 'healthiest period' in the life-cycle. The interface between social ecology, pubescence and psychosocial development leads to a number of diseases and disorders that challenge the traditional resources of the average health practitioner. 
In a recent report on health issues in today's youth, a group of opinion leaders from American business, higher education and the military expressed a consensus concern about health issues such as obesity, poor mental health including depression, drug use, risky sexual practices and lack of resilience. ${ }^{1}$ On the positive side, there was a general agreement that today's teens are far more knowledgeable about their health and what would help to improve it. From a business point of view, obesity led to increased risks for diabetes and hypertension, with absenteeism and increased insurance costs, while mental health issues, primarily depression and stress, lessened productivity and increased the use of short term disability, as well as family and medical leave. It was pointed out that the United States military, often the employer of last resort for at-risk youth, now refuses entry to over half of the youth recruits due to health issues. A recent study from the U.S. Department of Defence reported that $70 \%$ of female recruits and $62 \%$ of male recruits failed to qualify for military service because of physical or mental health conditions. ${ }^{2}$ Opinion leaders agreed that there needs to be a new paradigm to improve the health of adolescents - one that makes a greater investment in prevention through wellness education and skills training. Like any prevention, these approaches need to go beyond the schools, health centers, family environments and recreational settings. The approaches need to create healthy lifestyles within a culture of health.

In this book, Dr. Paperny emphasizes a proactive paradigm, a paradigm of anticipatory guidance based on our knowledge of development and disease. His approach is not one which excludes our role of intervention, but one that integrates prevention into the clinical visit. He promotes a model that goes beyond culture, language and community, a model that is universal and timeless - one that makes an impact on the lives of young people not only in the present, but translates into a preventive investment in their future. It is a model that gets more 'bang for the buck' - a consideration of paramount importance in the contemporary medical marketplace.

The Handbook of Adolescent Medicine and Health Promotion draws on Dr. Paperny's own clinical experience as a physician working with adolescents for over 30 years. He provides practical clinical approaches that really work. He discusses approaches to comprehensive health screening and evaluation, how to impact health choices and behaviors, and integrate issues of education and health promotion. This book is a unique combination of Pediatrics, Internal Medicine, Gynecology and Psychology. It addresses the contemporary issues facing youth in this millennium, including new technology and socio-cultural matters. The emphasis is not on the subtle diagnostics and complex subspecialty concerns, nor conditions which Pediatrics or Internal Medicine routinely manages with standard clinical guidelines (that can be found in textbooks or online), but rather, "uniquely adolescent" health applications.

This handbook will be useful for health providers, residents, and health care students of all specialties involved in the clinical care of adolescents and young adults. In 
addition, it can be a valuable resource tool for other interdisciplinary or lay practitioners who have regular contact with youth, and who want to more effectively promote their health and well-being. Since young people are usually influenced by many paramedical specialties as well as parents, teachers and clergy, this book will be useful to the wide variety of individuals who shape their daily health choices and actions.

Within the subspecialty model of medicine, adolescent medicine may best be thought of as the geriatrics of pediatrics! Within such a model, approaches to adolescent health care must, at a bare minimum, be comprehensive, but at its best, be integrative, emphasizing behavioral, prevention and health promotion issues. This perhaps is the single most distinguishing characteristic of the practice model of adolescent medicine as compared to those of other subspecialties. This book takes up the challenge of documenting this approach by providing practical clinical information and scenarios in an easy-to-use format. If your quest is to improve health outcomes, habits of wellness and to help adolescents and young adults get the most out of life, then this Handbook is an excellent starting point!

Richard G MacKenzie MD, FAAP, FSAHM

Director (Emeritus) Division of Adolescent Medicine

Medical Director, International Programs, Children's Hospital of Los Angeles

Associate Professor Pediatrics and Medicine, University of Southern California Keck School of Medicine

\section{References}

1. Frohnen BP, McManus MA, Limb SJ, Straus CR. (2010). Concern for Our Teens: Opinion Leaders Speak Out On Adolescent Health. National Alliance to Advance Adolescent Health, Report Number 4, July 2010. (Washington DC).

2. Lewin Group. (2005). Qualified Military Available: New Estimates of the Eligible Youth Population. Prepared for Accession Policy, Office of the Under Secretary of Defense (Personnel and Readiness) (The Lewin Group, Human Resources Research Organization, Falls Church, VA). 
This page intentionally left blank 


\section{About the Author}

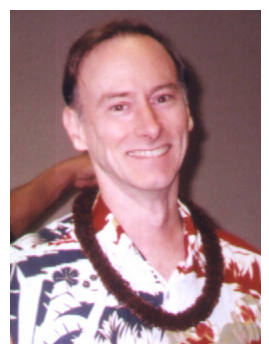

\section{David Paperny}

David Paperny, M.D. has been a Clinical Professor of Pediatrics for the John A. Burns School of Medicine at the University of Hawaii, and Director of Kaiser Permanente Adolescent Services in Hawaii for nearly 30 years. He received his medical education at University of California Los Angeles School of Medicine, completed his pediatric residency at Kapiolani-Children's Medical Center, and did his fellowship training in Adolescent Medicine at University of Washington in Seattle. He is a Fellow of the American Academy of Pediatrics and member of the Sections on Adolescent Health as well as Computers and Technology. He is a Fellow of the Society for Adolescent Health and Medicine, a certified Consultant for the Amerian Society of Clinical Hypnosis, board certified in Brainwave Biofeeedback, and a forensic medical consultant for the Hawaii Sex Abuse Treatment Center. Topics of his many publications include medical information technology, computerized health screening and assessment, as well as using computers and multimedia for health education. He has published many software programs and video-DVD programs on diverse topics such as sex education, teen parenting prevention, health assessment, asthma care skills, and parenting skills. He developed the Teen and Young Adult Checkup, a unique approach to health evaluation and education using computers, paramedical health counselors, and nurses to provide comprehensive adolescent preventive health services. His practice in Adolescent Medicine has included medical management with a focus on health education and promotion, sex education, health psychology of adolescence, biofeedback, stress management and personal empowerment. 
This page intentionally left blank 


\section{Contents}

Preface vii

Foreword $\quad$ ix

About the Author $\quad$ xiii

1. Medical and Paramedical Visits 1

2. Growth and Development 29

$\begin{array}{ll}3 . & \text { Dermatology } \\ & 47\end{array}$

4. Chronic Disease Management 63

5. Fatigue and Psychosomatic Illnesses 93

6. Psychology and Behavior 123

7. Adolescent Sexuality and Reproductive Health 171

8. Orthopedic Conditions and Sports 209

9. Practice Management and New Technologies 223

10. Health Promotion 247

Appendix $\quad$ Youth Health Program Software 259

$\begin{array}{ll}\text { Index } & 271\end{array}$ 